\title{
A TRIBUTAÇÃO E DIREITOS FUNDAMENTAIS QUE REALIZAM OS VALORES DA LIBERDADE, IGUALDADE E SOLIDARIEDADE
}

\author{
THE TAXATION AND BASIC RIGHTS THAT CARRY \\ THROUGH THE RIGHTS OF FREEDOM, \\ EQUALITY AND SOLIDARITY
}

\author{
Marlene Kempfer Bassoli*
}

\begin{abstract}
Resumo: $O$ fenômeno dos direitos humanos tem maior destaque a partir dos séculos XVII e XVIII por meio dos embates filosóficos, sociológicos e jurídicos em torno da doutrina do direito natural. O tema evoluiu de modo acelerado após a $2^{\circ}$ guerra mundial. As conquistas foram atingidas no campo dos direitos individuais, políticos, sociais, transindividuais e, no estágio atual, a pauta éo direito ao desenvolvimento dos povos no âmbito social, cultural, político e econômico. Um estudo panorâmico dos ordenamentos jurídicos, em diferentes momentos e Estados da história da civilização contemporânea, permite constatar que os direitos humanos foram contemplados por normas jurídicas, portanto, trazidos por meio do processo da positivação aos ordenamentos jurídicos como direitos fundamentais. $\mathrm{Na}$ condição jurídica de direitos fundamentais viabilizam condutas que realizam valores fundamentais. Devem ser tutelados pelo Estado e contra o poder do Estado. As considerações neste estudo serão no sentido de construir uma interpretação que aponte o dever constitucional imposto ao Estado brasileiro para, por meio das normas tributárias, viabilizar condutas que positivam os valores da liberdade, igualdade e solidariedade realizadores de direitos fundamentais.
\end{abstract}

Palavras-Chaves: Valores Jurídicos, Direitos Fundamentais, Tributação, Positivação.

Abstract: The phenomenon of human rights has showed up since eighteenth and nineteenth centuies through the philosophical, sociological and juridical clash round of natural law doctrine. The theme evolves aceleratly after Second World War. Conquests were stricken in areas like individual, political, social, transindividual rights and, nowadays, the agenda is the right of development of the people

"Doutora em Direito do Estado-Direito Tributário, pela PUC-SP. Professora dos programas de Mestrado em Direito da Universidade Estadual de Londrina-UEL/PR e da Universidade de Marília-UNIMAR/SP 
in social, cultural, political and economical areas. A panoramic study about legal systems in different moments and different States of the contemporary history of the civilization, leads to see through that human rights were contemplated by laws, for this reason, is were brought through of the confirmation process to the juridical systems like fundamental rights. They must be protected by State and against the State's power. Considerations in the present study will must to built an interpretation that aim the constitutional owe of the Brazilian State to, through of the tributaries laws, it enables conducts that confirms the values of liberty, equality and solidarity that achieve of fundamental rights.

Key-Words: Juridical Values; Fundamental Rights; Tributation; Confirmation.

\section{INTRODUÇÃO}

Os valores da liberdade, igualdade e solidariedade são valores prestigiados em nível universal. Contemporaneamente várias condutas que os realizam são consideradas como direitos fundamentais. A inefetividade destes direitos é um reclamo no plano jurídico e dos cidadãos. $\mathrm{O}$ estudo para demonstrar que há possibilidade jurídica para que se realizem sempre é estimulante, pois, instiga a esperança. As normas jurídicas tributárias de nível constitucional mostram o caminho para realizar os valores jurídicos destacados que se realizam em direitos fundamentais. É uma questão de decisão política governamental da União, Estados, Distrito Federal e Municípios exercer a competência tributária produzindo normas tributárias com esta finalidade.

\section{ASPECTOS ONTOLÓGICOS E GNOSEOLÓGICOS DOS VALORES A PARTIR DOS ESTUDOS DE NICOLAI HARTMANN APRESENTADOS POR JOÃO MAURÍCIO ADEODATO}

O estudo sistematizado dos valores constitui um conhecimento construído a partir da segunda metade do século XIX, embora a preocupação com o tema seja tão antiga quanto a humanidade. Apesar 
de ser uma disciplina recente ${ }^{1}$ já tem denominação própria que é a Axiologia.

Com o propósito de conhecer aspectos da teoria geral dos valores, para depois se concentrar na axiologia jurídica e demonstrar que os direitos fundamentais são resultantes da positivação de valores, faz-se necessário promover o encontro dos dois termos que permitem este conhecimento: o objeto, através de estudos da ontologia dos valores e o sujeito cognoscente, através dos estudos da gnoseologia dos valores.

Sobre o objeto que se quer conhecer, que são os valores, as investigações são para responder perguntas sobre em quais das esferas ontológicas do ser os valores podem ser localizado? A esfera dos seres reais ou dos seres ideais? Ou há uma terceira esfera própria dos valores? Quanto ao sujeito que os quer conhecer, os estudos são no sentido de definir como o homem consegue apreendê-los: é um conhecimento a priori ou a posteriorr? Podem ser conhecidos através da intuição sensível? Intelectual? emocional?

Muitos estudiosos se dedicaram para apresentar suas respostas. Dentre os estudos da ontologia dos valores, nesta pesquisa, serão destacados os estudos da ontologia do ser em geral de Nicolai Hartmann, a partir da apresentação de João Maurício Adeodato (1996. cap. 5), expondo-se as seguintes principais concepções:

a) todo ser pertence a uma ou outra esfera modal: realidade ou idealidade;

b) todo e qualquer ente é dotado de essência e existência não importando se o ente é real ou ideal;

c) a realidade ou a idealidade são modos do ser. A essência e existência são momentos do ser;

d) não são somente os entes da esfera real que existem; os entes da esfera ideal têm sua maneira de existir. São regidos por categorias (princípios) diferentes;

\footnotetext{
${ }^{1}$ Os valores já eram discutidos por pensadores como Sócrates, Platão, Aristóteles e os escolásticos. $\mathrm{Na}$ filosofia considerada da época moderna e contemporânea, entre tantos outros que deram importante contribuição para a Filosofia dos valores cite-se Kant; Lotze que introduziu o conceito de valor na Filosofia alemã; Brentano; Edmund Husserl; W. Windelband; Max Scheler; N. Hartmann. Do México temos Risieri Frondizi. Da Argentina Carlos Cossio. Do Brasil Miguel Reale e João Maurício Adeodato, estes com especificidade para o campo jurídico.
} 
e) há uma inter-relação entre a essência e a existência: a essência de um ente depende da existência e esta depende daquela;

f) a esfera real tem características próprias que a diferencia da esfera ideal:

g) individualidade, pois somente o ente real é material. Não há dois entes reais iguais. Cada um possui características próprias, são peculiares;

h) temporalidade, sendo que estão sujeitos ao tempo, portanto são mutáveis, sendo este o fator da processualidade; o ente real permanece no processo e as mudanças ocorrem em diferentes velocidade, por isto é possível registrar as mudanças, sendo este o fator denominado de identidade; o ente real é sujeito ao processo de mudança que ocorre em dois extremos: o ente surge e desaparece, sendo este o fator que denomina de limitação.

i) a esfera real é composta de esferas superpostas: a inorgânica e a orgânica, que correspondem ao mundo físico e a anímica e espiritual que correspondem ao mundo psíquico;

j) a esfera ideal é composta de esferas de mesmo nível ontológico: a das essências fenomenológicas, da matemática, da lógica e a dos valores;

k) o vínculo entre estes dois mundos se dá na medida em que a esfera ideal penetra na esfera real, permitindo sua construção.

O debate filosófico quanto à ontologia do ser em geral não será enaltecido neste trabalho. O corte será no sentido de expor algumas das concepções filosóficas para a ontologia dos valores. Conforme sistematização de João Maurício Adeodato (1996) as posições filosóficas podem ser reunidas em dois grupos:

1) concepção monística, que inclui todos os entes, inclusive a natureza, num mundo indivisível, regido pelo princípio ontológico fundamental da lei da causalidade;

m) concepção dualista, para quem os objetos estão reunidos no mundo da natureza ou real, compreendendo o reino animal, vegetal e o mineral; e, em outra porção, a esfera do mundo humano, onde está a ética. No primeiro mundo estão as leis naturais e o determinismo. No mundo da ética estão as normas da cultura, da liberdade, enfim, regido por normas humanas. 
Embora classificada por cientistas como aporia, o debate já antigo, entre monistas e dualistas oferece recursos didáticos para reunir os diferentes pensamentos sobre a axiologia.

Os monistas não encontraram eco diante da maioria dos estudiosos dos valores, pois não distinguem uma esfera específica para a ética, para as relações humanas e sociais. Uma das suas leis básicas, a da causalidade, poderia ser aplicada indistintamente, para qualquer campo do conhecimento. Constata-se, contemporaneamente, um recuo no entendimento sobre pretensão de universalização dos seus postulados.

Para a corrente dualista as questões axiológicas estão reunidas em duas direções (ADEODATO, 1996):

a) dos pensadores subjetivistas reunidos sob o título de subjetivismo axiológico para quem o objeto não é por si só valioso e o valor, provem de uma valoração do sujeito, conforme o prazer ou desprazer que este objeto possa lhe causar;

b) dos pensadores objetivistas reunidos sob o título de objetivismo axiológico, que defendem existir uma fonte externa ao sujeito que fornece parâmetros para separar os valores dos desvalores. Este grupo abriga as vertentes:

1. histórica, para quem os valores são criados pelo homem através do processo histórico-cultural;

2. ontológica, para quem os valores fazem parte de uma das regiões do conhecimento, com categorias próprias, isto é, regidos por princípios básicos que os ordenam. Se os valores existem, podem ser descobertos e não criados pelo homem.

Decidiu-se, para fins deste estudo, pela vertente da ontologia dualista, do objetivismo axiológico, admitindo como corte metodológico que os valores estão junto à esfera ideal, no mesmo nível das essências fenomelogógicas, das entidades matemáticas e lógicas.

Para Nicolai Hartmann, conforme relata Adeodato (1996), considera os estudos gnoseológicos subordinados aos ontológicos. Admitindo a existência de entes reais e entes ideais. O conhecimento dos objetos reais não é exclusivamente a posteriori, porque os princípios que o regem são sempre do mundo ideal, portanto, é conhecimento a priori. 
Defende que o conhecimento é um ato transcendente e que há o ato gnoseológico, sempre mais neutro, objetivo, estimulado pela intuição sensível e intelectual em que o objeto permanece externo ao sujeito, intocado. Há, também, o ato teleológico estimulado pela intuição emocional, em que o objeto é interiorizado, envolvendo a parte subjetiva do homem.

Alerta que não há atos puramente gnoseológicos ou somente emocionais, uma vez que não é possível postar-se com completa neutralidade diante do objeto ou fenômeno a conhecer.

Constrói proposições a respeito do conhecimento dos valores, cujos aspectos relevantes para este estudo, podem assim ser resumidos:

- considerando que os valores estão no mundo ideal, o conhecimento deles será sempre a priori, mesmo que se revele diante de um fato real através da emoção;

- os valores podem ser intuídos no nível do mundo anímico no estrato espiritual, onde localiza o homem, ser com consciência. Ele é o ser espiritual que serve de canal de aproximação da esfera real e a esfera ideal, especificamente dos valores;

- o homem une a idealidade e a realidade, quer seja pelo conhecimento ou na realização dos valores. Ele é um ser real, portanto, com as características da individualidade e da temporalidade;

- o homem é um ser individualizado, com sentimento, vontade, autoconsciência;

- o homem tem necessidade de se inter-relacionar com os membros da coletividade. É a intersubjetividade que caracteriza este ser espiritual, que inserido na realidade espacial e temporal, constrói a história;

- o homem enquanto indivíduo ou se relacionando manifesta-se, ou seja, "qualquer ação, todo discurso, qualquer expressão de conduta do indivíduo já é uma objetivação, um ato de exteriorização [...]" (ADEODATO, 1996).

Para Nicolai Hartmann (apud ADEODATO), o valor é captado pelo homem e separa-se de quem o captou e lhe deu significado. Penetra na intersubjetividade e adquire um significado. Ao ser vivenciado já está objetivado, mas pode não ser consolidado. A consolidação é que dará ou não ao valor o qualificativo de independente ou dependente, 
respectivamente. Quanto mais tempo o valor permanecer, mais independente será do espírito vivo que o percebeu e vivenciou. Após ser objetivado passa a compor a história do homem que é real.

Acrescenta que o conhecimento dos valores é em um único ato, sobremodo emocional e secundariamente racional. Embora a intuição axiológica ocorra em cada sujeito, este fato não autoriza afirmar que não sejam objetivos. A objetividade fica evidente à medida que há valores que permanecem na esfera ideal e aqueles não vivenciados, não significa dizer que eles não existam. Assim, defende que os valores são percebidos fenomenicamente, análogo ao ato de conhecimento que se dá por meio de um ato transcendente. Alerta, que é diferente do ato transcendente gnoseológico, pois o sujeito se aproxima dos valores e os insere na realidade através de um ato teleológico estimulado pela intuição emocional.

Busca aplicação do método fenomenológico e afirma que este ato teleológico pode ser dividido em três momentos:

a) intui emocionalmente o valor e através de um ato de conhecimento,

da intuição intelectual, decide como orientará sua ação, determinando um fim a ser atingido;

b) após, escolhe os meios para atingir o fim estabelecido;

c) finalmente, há a realização do valor no mundo real

Adeodato (1996, p. 146) apresenta um esquema da perspectiva gnoseo-axiológica de Hartmann:

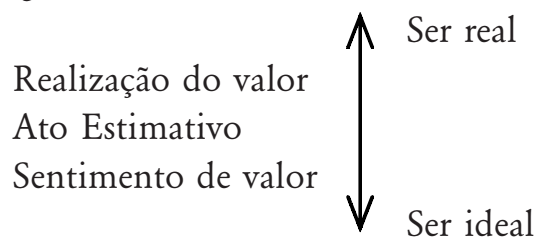

Conclui que para conciliar a afirmação de que o conhecimento dos valores é via emocional e racional, deve-se percorrer o caminho fenomenológico do ato valorativo:

a) fase mais importante é a do impacto emocional diante de algo. É momento desligado da reflexão, quando ocorre o contato do sujeito com o dever ser ideal, através da intuição emotiva; é a consciência do valor e não a de princípios; não é uma visão pura do valor, mas um sentimento que existe independentemente da experiência; 
b) segue a etapa da reflexão, em que o sujeito usa o raciocínio, estimulado pela intuição intelectual. Embora ainda sob o impacto da intuição emocional;

c) o sujeito procura a fonte do sentimento de valor que apreendeu. É o momento predominantemente intelectual, denominado de ato gnoseológico, em que o valor é efetivamente objeto de conhecimento.

\subsection{O Direito e os valores}

Os valores estão presentes, sempre, nas relações intersubjetivas, quer na construção gnoseológica do ser espiritual de Hartamann (apud ADEODATO, 1996); na necessidade de vivenciá-los na realidade social de Carlos Cossio (1946) e Miguel Reale(1994); na influência das situações circunstanciais (sociais, culturais) em que se encontra o objeto e o sujeito a que se refere Risieli Frondizi (1979); na ênfase ao aspecto da imediaticidade do conhecimento pela emoção do homem, que é provocada pela vivência, conforme Johannes Hessen (1974).

Esta intersubjetividade é identificada, também, no momento jurídico da vida humana, portanto, é possível acolher as conclusões filosóficas e filosófico-jurídicas para este campo do conhecimento.

Conforme Adeodato (1996) ao expor os estudos de Hartmann, o direito pode ser conceituado como um fenômeno real e espiritual, dirigido por valores ideais, inseridos na realidade. Delimita que a ciência do direito não tem por objeto de estudo a pesquisa dos valores e sua hierarquia e sim de que toma como indiscutíveis pressupostos axiológicos e estabelece seu próprio esquema de produção normativa. Acredita num auto-aperfeiçoamento ético, que no campo do direito, se dará pela influência da esfera axiológica sobre a esfera real. A partir destas premissas, as construções filosóficas que Hartmann fez em torno da ontologia e gnoseologia axiológicas aplicadas ao direito e que serão consideradas são as seguintes:

- todo direito caminha para o direito ideal, que corresponde à esfera do dever ser ideal da ontologia dos valores. Ao ser projetado na realidade, instiga ou inibe comportamentos em busca da realização de valores. 
- o valor inicia sua trajetória na realidade por meio do homem, que no seu agir é que faz a ponte entre a conduta real e os valores ideais.

- o homem tem necessidade de se relacionar com outros seres espirituais, formando uma coletividade. Estabelecem-se as relações intersubjetivas que permitem a identificação dos fenômenos sociais, entre eles o Direito e a criação da história.

- a interpessoalidade, por vezes, ultrapassa os interesses do indivíduo e por isto as relações nem sempre estão em harmonia. Surge o poder jurídico-político, para interferir com mecanismos contra o individualismo. Este poder é um mecanismo para proteger-se do individualismo. As exteriorizações do relacionamento humano são as fontes que permitem a criação do direito.

- as relações intersubjetivas lidam com valores que se pretende consolidar, proteger. É o momento em que se recorre à norma jurídica escrita. É o direito real, fenômeno empírico guiado por valores ideais.

- a norma positiva, com o valor que jurisdicizou aprisiona no presente e para o futuro. Contra este aprisionamento é possível defesa, ou seja, não aceitando os valores que herdou. É a dinâmica do fenômeno jurídico em busca, incessante, pelo autoaperfeiçoamento.

- os valores apreendidos pelo Direito e apresentados sob forma de enunciados deônticos, são os mínimos indispensáveis para realizar outros valores, colocados em nível mais alto na tábua de valores de uma coletividade. Assim como há uma hierarquia dos valores em geral, é possível estabelecer uma hierarquia entre os valores captados e materializados pelo Direito. A codificação permite criar instituições como a sanção organizada, o constrangimento pela violência legal e outras, para defesa dos valores captados e selecionados para reger as relações intersubjetivas.

- sendo o Direito dirigido por valores positivados, e para conhecer aqueles aprisionados pelo instrumento da codificação, segue-se a teoria gnoseológica geral dos valores: é predominantemente intuitivo (pela via emocional), mas também racional. Captar o valor positivado é, portanto, ato teleológico e intelectual. 


\section{POSITIVAÇÃO DOS VALORES JURÍDICOS NA PERSPECTIVA DE DIREITOS FUNDAMENTAIS}

Os valores ao serem vivenciados nas relações humanas, instigam comportamentos valiosos. Estes comportamentos permitem identificar uma das possíveis realizações de determinado valor. Um homem, por exemplo, quando recolhe do chão um outro homem machucado, tem um comportamento qualificável como de solidário, tendo realizado nesta oportunidade, uma das inúmeras vivências reais do valor solidariedade. Outro homem, diante de mesma situação, poderá deixar o homem no chão, sendo esta omissão um comportamento de desvalor ou de não solidariedade. Estas descrições permitem afirmar que no plano das relações humanas, ao vivenciar o valor liberdade, tem-se a possibilidade de comportamentos que realizem valores ou desvalores.

$\mathrm{Na}$ história das civilizações há registros que permitem concluir que, infelizmente, os humanos, nas suas vivências, nem sempre têm comportamentos valiosos, mesmo que sendo por isto recriminado por ordens normativas religiosas, éticas, costumeiras. Talvez motivados por esta constatação, buscou-se outro mecanismo para estimular a realização de comportamentos valiosos e sancionar aqueles que por ação ou omissão realizam desvalores.

O Direito é um dos possíveis caminhos para viabilizar a realização de valores, uma vez que tem mecanismos para tanto. Compõem o ordenamento jurídico as normas jurídicas que trazem o instrumento da sanção e, por meio do Estado, possibilitam punir os comportamentos que não realizam valores indicados e que se quer preservar. Para tanto é necessário que os valores presentes nas relações humanas sejam valores jurídicos. É possível trazer os valores e desvalores do plano fático das relações humanas onde é vivenciado, ao plano jurídico. O meio será percorrer o processo de positivação, ou seja, produzir normas jurídicas e em suas estruturas sintáticas estarão identificadas as condutas que realizem valores (condutas jurídicas) e as que realizam desvalores (condutas antijurídicas).

O percurso desta positivação será diferente, conforme seja o modelo de Governo que cada nação escolheu. Em um governo republicano, como é o modelo do Brasil, a decisão sobre quais os valores e os desvalores que devem reger as relações intersubjetivas será construída 
em um processo democrático representativo. $\mathrm{O}$ conjunto dos valores escolhidos e das condutas jurídicas e antijurídicas normatizadas irá compor o ordenamento jurídico nacional.

Para a doutrina hartmanniana, o Direito toma os valores como pressupostos, não sendo objeto de investigação sua ontologia ou o seu processo de conhecer. $\mathrm{O}$ direito tem seus mecanismos próprios para, através da sanção estatal, obrigar ou permitir condutas que realizem os valores selecionados e proibir condutas de desvalor.

Uma vez qualificados como valores e desvalores jurídicos, por meio da positivação, será possível tomá-los como objeto de estudos. Este será um dos planos da Filosofia do Direito e da Ciência do Direito. Tais estudos, entre outras conclusões, permitirão apontar a hierarquia dos valores jurídicos e o seu papel na interpretação do Direito, de modo que, ao serem produzidas as normas jurídicas abstratas e gerais e as concretas e individuais sejam prestigiadas as condutas humanas que os realizem.

A tábua de valores sociais pode ou não coincidir com a tábua de valores jurídicos. Esta é uma decisão política que será tomada por ocasião da positivação. É certo que a história humana, a partir da modernidade, recortada no marco da proposta de organização política construída pelo "contrato social", mostra a preocupação de buscar, por meio do Estado, a realização dos valores que compõem da tábua de valores sociais.

No que diz respeito aos estudos dos direito humanos, as buscam foram no sentido de garantir condutas que viabilizassem valores considerados fundamentais. As vivências políticas e sociais, especialmente a partir dos séculos XVII e XVIII, na Europa, com a ascensão da burguesia capitalista, a construção do Estado Moderno, confirmam este objetivo.

Entre as sistematizações da Filosofia e da Filosofia do Direito, são apontadas duas importantes contribuições para os estudos dos direitos humanos: a primeira é a vertente do jus naturalismo, defendendo que os direitos humanos derivam da lei natural; de que são anteriores e superiores às limitações da sociedade; que eles têm primazia sobre os direitos positivados. A segunda vertente também chamada de histórica, defendendo que os direitos humanos são variáveis e relativos conforme o tempo, o lugar e o grau do desenvolvimento da sociedade, portanto, 
os direitos humanos têm por fundamento as necessidades humanas e se modificam conforme estas necessidades.

$\mathrm{O}$ embate entre as duas doutrinas, longe de terminar, expõem pontos em comum. Destaque-se a defesa de que as condutas que realizam tais direitos devem ter especial atenção na vivência humana, uma vez que são considerados como realizações de valores fundamentais.

Estudos dos ordenamentos jurídicos modernos e contemporâneos, em diferentes Estados, tanto os nacionais quanto os internacionais, permitem constatar que os direitos humanos estão contemplados em normas jurídicas. Em diferentes graus foram trazidos como direitos jurídicos por meio da positivação a partir e para o plano das relações humanas. Passaram à denominação de direitos fundamentais. Nesta condição jurídica devem ser tutelados pelo Estado e contra o poder de dominação do Estado.

Considerando-se uma avaliação axiológica do tema, a partir da Declaração de Direitos do Bom Povo da Virgínia (1776) e da Declaração Francesa dos Direitos do Homem e do Cidadão (1789), constata-se que, inicialmente, buscou-se positivar o valor liberdade tutelando, por meio de normas jurídicas, condutas individuais que garantissem a sua realização. Foram desenvolvidos estudos e propostos modelos de Governo, de Estado e Econômicos que protegessem a liberdade individual. Foi o auge do liberalismo filosófico, político e econômico. Constatou-se que o valor liberdade ao ser positivado por meio das estruturas dos referidos modelos projetou o individualismo humano e reduziu as possibilidades de realização de outro valor fundamental que é o valor igualdade.

Movimentos sociais e políticos importantes se engajaram em torno de estudos e propostas com outros parâmetros sociais, políticos e econômicos para privilegiar as condutas que realizem o valor igualdade. Foi o momento do socialismo filosófico, político e econômico. Por meio da positivação destas novas estruturas sobressaíram-se as conquistas dos denominados direitos mínimos de igualdade e garantidos pelo Estado. Embora qualificadas por estudiosos como modelos utópicos, talvez tenha sido o período contemporâneo da humanidade em que os direitos fundamentais pudessem ter sido qualificados como muito próximos aos direitos naturais do homem.

A luta pela realização do valor igualdade é mais desafiadora do 
que a luta pela realização do valor liberdade. Esta afirmação se faz sob a ótica de que para realizar a igualdade é preciso conviver com as diferenças, enfrentar as desigualdades para a igualdade se impor. Para tanto, deve-se exercitar o valor da solidariedade. As condutas solidárias viabilizam condutas de igualdade. As condutas de liberdade individual nem sempre.

As conquistas dos direitos fundamentais, denominados de direitos sociais e transindividuais representam a positivação dos valores da igualdade e da solidariedade.

Os valores não são excludentes, ou seja, a convivência humana demonstra que diferentes valores compõem as diferentes tábuas de valores individuais e coletivas. Elas expõem que os valores estão ordenados em grau de importância e que se modificam no tempo. Estas constatações devem ser consideradas no momento da positivação de modo que o Direito possa ser mecanismo de mudança e de estabilidade.

A convivência social e jurídica com os valores da liberdade, da igualdade e da solidariedade estimula um conjunto de condutas que realizam um valor superior: o valor da dignidade da pessoa humana.

\section{NORMAS TRIBUTÁRIAS E A CONTRIBUIÇÃO PARA EFETIVAR DIREITOS FUNDAMENTAIS}

É antigo o reclamo universal quanto a inefetividade dos direitos fundamentais. A responsabilidade é atribuída ora aos indivíduos ou à sociedade, ora ao Estado e por vezes a ambos. O fato é que ainda na atualidade, depois de muitos séculos, continua a busca por mecanismos de efetividade destes direitos.

O modelo do liberalismo econômico e político, que defende um Estado mínimo, importante para tutelar as liberdades individuais e políticas que este movimento positivou, não foi suficiente para viabilizar condutas que realizam outros valores fundamentais. A realidade atual comprova que a presença de um Estado maior, forte, interventor, é indispensável para concretizar conquistas de direitos fundamentais. Para tanto, será útil identificar os instrumentos disponíveis ao Estado para cumprir com mais esta atribuição.

Entre as atribuições que compõem a essência do Estado, está a de 
produzir normas jurídicas que impõem aos cidadãos o dever de pagar tributos. A arrecadação destes dinheiros tem várias finalidades, em especial, manter a estrutura estatal, justificável somente para realizar interesses públicos. Por meio dela é possível o próprio Estado viabilizar políticas públicas realizadoras de direitos fundamentais.

Além deste objetivo, é dever do Estado, no âmbito do direito de intervir nas relações privadas por meio da tributação, observar os enunciados constitucionais a partir dos quais se constroem normas jurídicas que indicam caminhos para a realização e preservação de valores fundamentais, destacando-se a liberdade, a igualdade e a solidariedade.

Para estudo dos instrumentos tributário que podem viabilizar condutas que realizem os valores referidos, serão consideradas as seguintes premissas:

1. direitos humanos contemporâneos são aqueles que já estão integrados à ordem jurídica brasileira, denominados de direitos fundamentais individuais, sociais e trans individuais;

2. os direitos fundamentais, ao longo da história humana, representaram e representam a positivação de valores universais, destacando-se, para este estudo, a liberdade, a igualdade e a solidariedade; o conjunto das condutas que os realizam possibilita realizar o valor superior da dignidade humana;

3. há uma ordenação constitucional de valores fundamentais e, aqueles acima indicados, estão colocados no ponto mais alto da tábua de valores jurídico-constitucionais; eles se positivam por meio de direitos objetivos como direito ao alimento; direito a moradia; direito a saúde, direito ao conhecimento, direito à liberdade, direito ao trabalho. Estes direitos garantem a dignidade humana mínima.

\subsection{Tributação e o valor liberdade}

$\mathrm{Na}$ Constituição Federal brasileira está indicado, a partir do seu preâmbulo, o valor liberdade como um dos valores jurídicos do Estado brasileiro. Ao indicar este valor entre os direitos fundamentais consagrase a conquista na luta dos povos pelo reconhecimento do direito à diversidade e também a um mínimo de liberdades individuais, protegidas por mecanismos jurídicos estatais. Pode-se conferir esta positivação no Art. 5ำ em vários de seus incisos. Tendo em vista o 
propósito desta pesquisa tem-se como destaques: a legalidade e a imunidade tributária.

O Art. 5ํㅡ, II, enuncia o direito a uma esfera reservada à liberdade de condutas privadas, sem interferência do Estado. A este direito contrapõe-se o dever do indivíduo de comportar-se conforme decisão estatal, vertida em norma jurídica, produzida em um processo legislativo. É a norma constitucional de que os destinatários da norma jurídica devem portar-se conforme seja conduta permitida, obrigatória ou proibida.

Esta liberdade é também assegurada diante da tributação nos termos do Art. 150, I, da Constituição Federal, na medida em que exige dos cidadãos a conduta obrigatória de pagar tributos conforme estiver determinado em norma jurídica. Expõe, também, o direito a condutas que não podem ser alcançadas pela tributação. Possibilita ao cidadão a liberdade de escolha entre condutas tributadas e não sujeitas à tributação. Nesta possibilidade está a raiz do direito ao planejamento tributário. Portanto, a norma constitucional denominada de Princípio da Legalidade Tributária além de delimitar com precisão condutas tributáveis, possibilita a realização concreta do valor fundamental da liberdade por meio do reconhecimento ao planejamento tributário.

Outras condutas que positivam a liberdade são tuteladas pela imunidade tributária. Conforme definição de Paulo de Barros Carvalho (2005. p. 185) a imunidade trata de competência tributária, ou seja:

classe finita e imediatamente determinável de normas jurídicas, contidas no texto da Constituição Federal, e que estabelecem, de modo expresso, a incompetência das pessoas políticas de direito constitucional interno para expedir regras instituidoras de tributos que alcancem situações específicas e suficientemente caracterizadas

O alcance deste instituto tributário é, também, proteger da tributação condutas que possibilitam realizar valores constitucionais. Por meio da imunidade exclui-se a possibilidade de produzir normas de comportamento cujo objeto seja o dever de pagar tributo. Esta norma constitucional tem por destinatários os entes federados e deve ser observada por ocasião do exercício da competência tributária

Conforme o disposto no Art. 5ª , IV e IX da Constituição Federal 
tem-se o direito à liberdade de expressão que é instrumento de comunicar o conhecimento no seu mais amplo sentido. Protege-se o direito fundamental à liberdade de manifestar opiniões, de expressarse através da arte, da palavra escrita, enfim, das mais diversas formas de expressão. Para a efetividade deste direito é correta a interpretação jurídica de que não importa o veículo utilizado uma vez que a cada momento estão disponíveis novas e múltiplas tecnologias. Os materiais, equipamentos, insumos, que são necessários para viabilizar condutas que promovam a liberdade de expressão devem estar protegidos pela imunidade. Este direito não pode ser inviabilizado ou restringido por normas de conteúdo tributário, conforme se reconhece a partir dos enunciados do Art. 150, VI, "d" da Constituição Federal.

Adiante, no Art. 5ㅇ, VI, tem-se a proteção ao direito fundamental da liberdade religiosa. É a consolidação da vitória das lutas pela separação da instituição Estado do poder religioso. Deve-se respeitar a liberdade de opção entre as mais diversas formas de manifestações da fé humana. Assim, toda estrutura material, pessoal, necessária e construída para a profissão desta fé estão protegidas da tributação, conforme se pode confirmar por meio do Art. 150, VI, "b" da Constituição Federal.

Neste mesmo Art. 5, XV, trata da liberdade de locomoção no território nacional, reconhecido como o direito de ir e vir. Esta liberdade será garantida a partir do momento em que se reconhece a titularidade do Estado sobre determinados bens qualificando-os como públicos e, em conseqüência, viabilizar o uso comum. Somente assim é que se compatibiliza a liberdade de locomoção com o direito constitucional à propriedade privada. Nos termos constitucionais a ninguém é dada legitimidade de locomover-se desrespeitando a propriedade privada. Para possibilitar a convivência destes dois direitos fundamentais são necessárias as vias públicas para uso comum. Esta liberdade tem especial tutela no ordenamento jurídico, bastando conferir que é assegurada por meio do habeas corpus e, as condutas que possam restringir ou inviabilizá-la são criminosas (seqüestro, cárcere privado).

No contexto tributário, o Art. 150, V da Constituição Federal imuniza a liberdade de locomoção. Permite a cobrança de pedágio pelo serviço de conservação da via pública e não pelo seu uso. Se assim não se interpretar estar-se-ia inviabilizando a liberdade ora 
tratada, confirmando-se um retrocesso histórico. Para não incorrer nesta inconstitucionalidade, diante da opção estatal de cobrar pedágio, deve-se assegurar um via pública como alternativa à via pública pedagiada. Com a via alternativa utilizada livremente por todos garantese a liberdade de locomoção e com a via pedagiada de uso específico e divisível, possibilita-se o usufruto para aqueles que assim o desejarem. Definir via alternativa é dever do Estado para que o cidadão possa ter garantido este direito que, certamente, está no rol dos direitos naturais do homem.

É garantia constitucional a liberdade para organizar-se sob qualquer forma de associação, nos termos do Art. 5ㅜ, XVII, inclusive, sob denominação de partido político conforme está no Art. 17. Por meio da instituição partidária é que será possível o exercício da cidadania passiva, permissão que está no Art. 14, § 3으, V. Filiar-se a partido político é condição para ser representante popular e participar democraticamente na formação da vontade nacional. Os partidos políticos são a célula mãe da democracia no Brasil. Desta forma, as iniciativas de formação partidária, de manutenção do pluripartidarismo, viabilizam o direito fundamental à liberdade política na versão da democracia. Portanto, o exercício das liberdades políticas deve ser protegido de qualquer mecanismo restritivo, entre eles o tributário. Assim está assegurado pela imunidade tributária do Art. 150, VI, "c".

\subsection{Tributação e o valor igualdade}

Em várias passagens do texto constitucional é possível apontar enunciados que indicam a presença do valor jurídico da igualdade. No modelo de Governo republicano, no modelo de Estado Federal, para as condutas estatais diante das relações internacionais, para as relações internas e internacionais no plano econômico, e, especialmente na condição de direito fundamental.

Filósofos, cientistas do Direito, da Ciência Política, da Sociologia, têm se debruçado para investigar o alcance do valor igualdade e a importância de enaltecer condutas que a efetivem.

Os estudiosos do Direito confirmam que é possível positivar como fato jurídico e antijurídico as condutas que realizem valores (igualdade) e desvalores (desigualdade). Assim, pode-se afirmar que por meio de 
normas jurídico-tribútárias positivadas em nível constitucional, o Estado no exercício da competência tributária, deverá produzir normas infraconstitucionais para que o valor igualdade alcance o plano das relações humanas.

No caput do Art. 5 e inciso I da Constituição Federal tem-se a igualdade formal, no sentido de que todos os destinatários de uma norma jurídica deverão a ela se submeter, sem qualquer distinção. Aplicada esta regra às normas tributárias, todos praticantes de evento tributários que, por força da incidência normativa, possam ser considerados fato jurídico tributário, devem figurar em relação jurídica tributária. Este é um dos sentidos que se pode atribuir às disposições do Art. 150, II.

Se a igualdade formal é da estrutura no modelo de Estado republicano, tem maior envergadura o valor igualdade na acepção de igualdade material. Para que este valor fique exposto em sua plena extensão exige-se que sejam consideradas as diferenças, as diversidades. Esta interpretação pode ser confirmada, mais uma vez, com as disposições do Art. 150, II que não permite tratamento desigual entre os iguais. Quaisquer mecanismos tributários ou não, que inviabilizem esta norma, serão inconstitucionais.

Por ocasião da indicação do tributo como fonte de receitas públicas, imediatamente a igualdade material passa a estar em pauta. É preciso definir critérios para selecionar aqueles que deverão pagar tributos. Sem esta definição ter-se-ia apenas a igualdade formal.

No Brasil, são considerados materialmente iguais para pagar impostos aqueles que têm capacidade contributiva nos termos do Art. $145, \S 1^{\circ}$. No texto constitucional, por exemplo, nos artigos 153, 155, 156 , estão indicadas as pessoas físicas ou jurídicas que preenchem este requisito.

Diante dos impostos há indicação constitucional de mecanismos tributários específicos para a realização do valor igualdade, tais como:

- as alíquotas progressivas: em razão do valor venal do imóvel para cobrar Impostos sobre a Propriedade Predial e Territorial Urbana (Art. $156, \S 1$, I); para diferentes valores da renda para tributar por meio do Imposto de Renda (Art._153, § 2드. I); para diferentes tamanhos da área rural para tributar pelo Imposto sobres a Propriedade Territorial Rural ( Art. 153,§ 4으, I); 
- a imunidade tributária frente ao Imposto Territorial Rural para pequenas glebas rurais (Art. 153, § 4은, II );

- tratamento tributário diferenciado para empresas de pequeno porte e microempresas (Art. 170, IX e Art. 179);

- a competência tributária para produzir normas de isenção.

Para as taxas a igualdade se viabiliza por meio do critério da retributividade. Deve ser indicado como contribuinte aquele que provoca uma despesa especial ao Estado pelo exercício do poder de polícia ou pela prestação de serviço público específico e divisível nos termos do Art. 145, II.

Com a contribuição de melhoria a igualdade se materializa ao serem selecionados aqueles que auferem valorização imobiliária em decorrência da construção de obra pública nos termos do Art. 145, III.

\subsection{Tributação e o valor solidariedade}

O valor da solidariedade inspira condutas de compartilhar, generosidade, incluir, possibilitar, universalizar e tem como desvalores o individualismo, egoísmo, excluir, impossibilitar.

Sob aspectos de direitos fundamentais este valor se realiza diante de diversas condutas reunidas, contemporaneamente, sob o título de direitos para todos. São aplaudidos pelos defensores do Estado do bem-estar social. Pretendem viabilizar direitos para todos à alimentação, conhecimento (educação), saúde, trabalho, lazer, segurança, moradia, indicados na Constituição Federal nos artigos 6a , 193, 196, 203, 205, 215. Nesta categoria estão também os direitos transindividuais. Para este estudo tem-se em vista aqueles pertinentes à preservação ambiental, ao desenvolvimento sócio-econômico sustentável, conforme enumera o Art. 225 da CF.

A atuação do Estado dirigida a possibilitar os direitos que positivam o valor solidariedade se verifica, por meio da tributação, quando recolhe dinheiro com a cobrança das contribuições sociais autorizada constitucionalmente para atender ações nas áreas de saúde, previdência e assistência social, nos termos dos artigos $195 ; 212$, § $5^{\circ}$ da CF; 85 e 90 do ADCT.

Para alcançar a efetividade dos direitos ora em consideração, há 
autorização constitucional (Art. 167, IV) para vinculação de receitas tributárias de modo que se reserve dinheiro que irá financiar ações viabilizadoras de tais direitos, por exemplo, a destinação ao Fundo de Combate à Pobreza instituído nos termos do Art. 80 do ADCT .

Também possibilita acesso a bens essenciais utilizar o mecanismo da alíquota seletiva autorizada nos Art. 153, § 3으, I (IPI), Art. 155, § $2^{\circ}$, III (ICM), Art._82, §§ $1^{\circ}$ e $2^{\circ}$ ADCT ( ICM e ISS). Por meio destas alíquotas os produtos, mercadorias e serviços são tributados de modo diferenciado. Alíquotas percentualmente maiores ou menores conforme critério de essencialidade. Com alíquotas menores tais bens tornam-se mais baratos e assim acessíveis à aquisição. Isto é constatável uma vez que, pelo fenômeno econômico da repercussão, os custos tributários são repassados ao preço final e assumidos pelo consumidor. Desta forma, as alíquotas menores ou até mesmo a isenção devem ser garantidas aos bens de consumo que sejam necessidades humanas mínimas.

Tratando-se de alimentos, aqueles que compõem a cesta básica, devem ser tributados conforme a norma constitucional da seletividade. Tratando-se de moradia, da mesma forma, para materiais essenciais à edificação em tamanho e padrão definidos como razoáveis para habitar. E assim para demais direitos fundamentais mínimos, proporcionandose acessos a cestas básicas de saúde (remédios para enfermidades comuns); para a cultura; para o ensino fundamental privado (Art. 208 e Art. 209), uma vez que o Estado tem atuado insuficientemente para atender a demanda.

Viabilizar condutas solidárias é dever do Estado, portanto, quando a sociedade civil se organiza para tanto, passando a atuar por meio de instituições no terceiro setor, tem direito à imunidade tributária (Art. 150, VI, “c").

Esta interpretação é extensiva a condutas de solidariedade para com o meio ambiente. A empresa quando, além de cumprir sua função social de preservar o meio ambiente (Art. 170, VI), toma mais atitudes de preservação ou de apoio a instituições ambientalistas do terceiro setor, poderá pleitear incentivos fiscais. È a empresa que têm condutas de responsabilidade social.

Quanto às ações do Governo para a tutela ambiental, podem ser sustentadas, em parte, pela cobrança de Contribuição de Intervenção no Domínio Econômico-CIDE (Art. 177, § 4º). Inclusive, esta 
arrecadação tributária tem vinculação para gasto em projetos ambientas conforme está no Art. 177, § 4º II, “b”. Com este mecanismo se possibilita, efetivamente, atitudes de proteção que são solidárias.

A propriedade é um direito individual, mas, somente justificável se cumprir função social. Esta qualidade é definida em nível constitucional no Art. 182, $\S \S 2^{\circ}$ e $4^{\circ}$ para a propriedade urbana, Art. 186 para a propriedade rural e Art. 170 III para atividades econômicas. Entre os requisitos para alcançar esta consideração estão a destinação da propriedade territorial para morar, para praticar atividades econômicas, produzir alimentos, cumprir normas de respeito ao trabalho, preservar meio ambiente, uso racional dos recursos naturais. São condutas de compartilhar, de universalizar, portanto, devem ser implementadas para que o valor solidariedade possa se realizar. As normas tributárias também devem estar dirigidas para estas finalidades. A Constituição federal determina que assim seja conforme é possível concluir a partir da interpretação do Art.153, § 4º para o ITR e Art. 156, § 1ํㅡ, I para o IPTU.

\section{CONCLUSÃO}

Embora a ciência do direito não tenha por objeto de estudo a pesquisa sobre os valores em geral e os toma como indiscutíveis pressupostos, conforme anota Nicolai Hartmann, alguns aspectos de orientação ontológica e gnoseológica dos valores servem para embasamento filosófico destes estudos: i) os valores existem, estão na esfera ideal, projetam-se sobre a esfera real, podem ser descobertos pelo homem, que faz a ponte entre a esfera ideal e a real; ii) nem todos os valores são captados pelo homem, mas não é nota essencial para sua existência a sua realizabilidade; iii)não sendo realizado no processo histórico, em determinado momento e lugar, não significa que não existam, isto é, da mesma forma que um círculo, que também está na esfera dos objetos ideais, não deixa de existir se não corresponder ao desenho de um ć́rculo perfeito; iv) o valor em sua plenitude não está ao alcance do indivíduo e mesmo quando captado na forma de dever ser ideal e alcançar o patamar do valor realizado individual ou coletivamente não se exaure, assim, sempre haverá a realizar, por exemplo, justiça, igualdade, fraternidade; v) por ser um ente ideal, o 
conhecimento do valor é a priori, ou seja, é um ato transcendente intuitivo e racional; vi) é intuitivo ao permite unir a esfera real com a ideal e é racional a partir do momento em que se procura a fonte do sentimento do valor.

O direito reúne as normas jurídicas dirigidas às condutas humanas, construídas a partir e para o plano das relações humanas. Tem por finalidade realizar valores. $\mathrm{O}$ caminho a percorrer entre o valor em si e a conduta que o realiza pode ser descrito também em linguagem jurídica. Por meio do processo de positivação haverá a juridicização de condutas que realizam valores (condutas jurídicas) e aquelas que realizam desvalores (condutas antijurídicas). Ambas compõem a estrutura sintática das normas jurídicas. Desta forma, pode-se afirmar que por meio das normas jurídicas tem-se condutas que permitem ou obrigam a realização e a preservação de valores e aquelas que proíbem a concretização de desvalores. Estas punidas com sanção jurídica.

Há valores que foram elevados à categoria de valores humanos fundamentais e sua realização, no plano das relações intersubjetivas, continua sendo objetivo dos povos. As condutas que permitem apontar a realização de tais valores podem ser reunidas sob o título de direitos naturais do homem. Ao serem positivados em normas jurídicas são denominados de direitos fundamentais.

Tem-se reconhecido os direitos fundamentais individuais que positivam, com prevalência, o valor liberdade; os direitos sociais e os transindividuais que positivam, com prevalência, os valores da igualdade e solidariedade; e, a partir das décadas de 70-80, o direito fundamental ao desenvolvimento dos povos, condição para os demais direitos fundamentais conquistados se efetivarem.

Entre os valores positivados em direitos fundamentais, para este estudo, se destacou os valores liberdade, igualdade e solidariedade. A opção se fez, pois o conjunto das condutas que os realizam permite afirmar que outro valor de superior hierarquia, simultaneamente, se concretiza: o valor da dignidade humana.

A inefetividade dos direitos fundamentais é uma constatação jurídica e fática generalizada. As normas de conteúdo tributário podem dar efetividade a determinados direitos fundamentais: 
i) o valor liberdade manifestado por condutas que realizam as liberdades de expressão, religiosa, locomoção, de organização plíticopartidária, é protegido da tributação por meio da imunidade. A esfera de liberdade privada também é tutelada pela norma constitucional-tributária que exige norma jurídica de incidência tributária para obrigar ao pagamento de tributo somente nas hipóteses tributárias indicadas;

ii) o valor igualdade enquanto igualdade formal diante da norma tributária, exige de todos os destinatários a sua obediência, sem distinção ou preferência. Enquanto igualdade material tributária se realiza aos serem selecionados critérios que possibilitem reconhecer diferenças. A capacidade contributiva seleciona cidadãoscontribuintes que realizam eventos descritos pela hipótese tributária denotativos deste critério para pagar impostos; a retributividade pelo exercício do poder de polícia ou prestação de serviço público específico e divisível, sendo o critério para selecionar cidadãoscontribuintes que pagarão taxas; a valorização imobiliária decorrente de obra pública é o critério para selecionar cidadãoscontribuintes para pagar contribuição de melhoria. Para alcançar a igualdade material por meio do imposto, há o mecanismo da alíquota progressiva e também o dever de tratamento tributário diferenciado para empresas de pequeno porte e microempresas;

iii) o valor solidariedade se realiza com condutas de compartilhar, de incluir, e possibilita a universalização de acesso e manutenção de direitos fundamentais para todos. O mecanismo das alíquotas seletivas possibilita que bens essenciais recebam a incidência tributária com alíquotas menores, portanto, acessíveis ao consumo por terem um valor menor. As normas tributárias que instituem contribuições sociais permitem arrecadação para financiar a seguridade social, onde estão condutas dirigidas à saúde, previdência e assistência social. A propriedade privada é aceita quando cumpre sua função social; no caso de ser urbana quando destinada, por exemplo, à habitação e sendo rural quando for produtiva, houver a preservação meio ambiente entre outros requisitos. A tributação da propriedade deve ser com alíquotas progressivas para alcançar esta finalidade. Ao cumprir o dever de estimular condutas solidárias o Estado não terá competência (imunidade) para tributar o 
patrimônio, a renda e os serviços da sociedade civil organizada atuante no terceiro setor.

Fica demonstrado que as normas jurídicas tributárias de nível constitucional também possibilitam a realização dos valores da liberdade, igualdade e solidariedade no plano das relações intersubjetivas. Diante da relevância jurídica dos direitos fundamentais, todos os entes federados, devem exercer plenamente as competências tributárias autorizadas em nível constitucional para a efetividade de tais direitos. Esta atribuição está imposta nos termos do Art. 23 da Constituição Federal à União, Estados, Distrito Federal e Municípios: zelar pela guarda da Constituição.

\section{REFERÊNCIAS BIBLIOGRÁFICAS}

ADEODATO, João Maurício. Filosofia do Direito: uma crítica à verdade na ética e na ciência. São Paulo: Saraiva, 1996.

CARVAlHO, Paulo de Barros. Curso de Direito Tributário. 17. ed. São Paulo: Saraiva, 2005.

COSSIO, Carlos. La plenitude del ordenamiento jurídico. Buenos Aires: Losada, 1946.

FRONDIZI, Risieri. ¿Qué son los valores? - Introducción a la axiologia. 3. ed. Mexico: Fondo de Cultura Econômica, 1979.

HESSEN, Johannes. Filosofia dos Valores. 4. ed. Coimbra: Gráfica de Coimbra, 1974.

REALE, Miguel. Introdução à Filosofia. 3. ed. São Paulo: Saraiva, 1994. 